\title{
Visitas Técnicas aos Centros de Referência Neonatal e Pediátrica em Saúde Terciária: Relato de Experiência
}

\author{
Soares, Lorena Sousa; Santos, Janaina Maria dos; Bezerra, Maria Augusta Rocha \\ Universidade Federal do Piauí — Iorenacacaux@hotmail.com
}

Introdução: Segundo Ministério da Saúde, a atenção em saúde é divida em três níveis: primária, secundária e terciária. Cada uma apresenta ações específicas, englobando aspectos da promoção, prevenção, tratamento, recuperação e reabilitação em saúde. Objetivo: Este trabalho apresenta como objetivo relatar a experiência de visitas técnicas aos centros de referência neonatal e pediátrica em saúde terciária realizadas na disciplina de Enfermagem na Saúde da Criança e do Adolescente. Métodos: As visitas foram realizadas nos turnos da manhã e tarde, no dia 16 de dezembro de 2013, na cidade de Teresina, capital do Estado do Piauí. o curso de Bacharelado em Enfermagem, citado neste trabalho, é ofertado no Campus Universitário da cidade de Floriano (PI), a cerca de $240 \mathrm{~km}$ da capital. a cidade dispõe de uma unidade hospitalar de pequeno porte voltada à saúde pediátrica e neonatal. Diante deste fato, as docentes da disciplina organizaram visitas agendadas previamente em serviços de médio e grande porte para que os discentes pudessem conhecer a organização destes serviços e proporcionar sugestões de melhoria na atenção à saúde pediátrica e neonatal dos usuários assistidos durante o estágio da disciplina. Resultados: a turma foi dividida em seis grupos e a observação dos serviços foi realizada a partir de um roteiro estruturado, desenvolvido a partir da realidade de cada instituição. na maternidade, centro de referência em neonatologia, os setores visitados foram: alojamento conjunto, Banco de Leite Humano e ala do Método Mãe-canguru. no centro de atenção terciária em pediatria, foram visitados: Unidade de Terapia Intensiva (UTI), enfermarias clínicas e cirúrgicas e Centro de Referência de Imunobiológicos Especiais (CRIE). em cada setor, enfermeiros, técnicos de enfermagem e demais profissionais, inseridos e com experiência na área, explicaram aos discentes, docentes e às monitoras da disciplina, pontos pertinentes e relevantes para um maior aprendizado $\mathrm{e}$ aproximação da teoria com a prática. um relatório será produzido pelos discentes para compilar os principais pontos observados. Conclusões: As visitas foram um momento único e peculiar, pois possibilitaram uma aproximação dos discentes à realidade de saúde terciária. a partir das mesmas, estes puderam vivenciar a assistência de enfermagem aos recém-nascidos e crianças em situação crítica e, assim, elencaram pontos importantes que podem ser aplicados à realidade local na qual estão inseridos.

Soares, Lorena Sousa; Santos, Janaina Maria dos; Bezerra, Maria Augusta Rocha. Visitas Técnicas aos Centros de Referência Neonatal e Pediátrica em Saúde Terciária: Relato de Experiência. In: Anais do Congresso Internacional de Humanidades \& Humanização em Saúde [= Blucher Medical Proceedings, num.2, vol.1]. São Paulo: Editora Blucher, 2014. ISSN 2357-7282

DOI 10.5151/medpro-cihhs-10286 